ISSN 1980-5098@@ DOI: http://dx.doi.org/10.5902/1980509831606

\title{
APTIDÃO EDAFOCLIMÁTICA PARA O MOGNO-AFRICANO NO BRASIL
}

\author{
EDAPHOCLIMATIC APTITUDE TO AFRICAN MAHOGANY IN BRAZIL
}

\author{
Derblai Casaroli ${ }^{1}$ Flávio de Oliveira Rosa ${ }^{2}$ José Alves Júnior $^{1}$ Adão Wagner Pêgo Evangelista ${ }^{3}$ \\ Barbara Vieira de Brito ${ }^{4}$ Diogo Silva Pena ${ }^{5}$
}

\begin{abstract}
RESUMO
O mogno-africano (Khaya ivorensis A. Chev.) é uma espécie arbórea, nativa do continente Africano, com boa qualidade de madeira, muito utilizada na confecção de móveis, na indústria naval, na construção de portas e portais, dentre outros. Tendo em vista que as condições de clima e solo são semelhantes entre a região de origem e o Brasil, pode-se inferir que o território brasileiro possui um grande potencial de cultivo. Este trabalho objetivou identificar zonas com aptidão edafoclimática para o mogno-africano no Brasil. A partir das variáveis, temperatura média, pluviosidade anual e tipos de solo, elaboraram-se critérios de seleção de regiões aptas, restritas e inaptas, para o adequado crescimento e desenvolvimento do mogno. Regiões que apresentaram temperaturas entre $23^{\circ} \mathrm{C}$ e $29^{\circ} \mathrm{C}$ foram consideradas aptas, com temperaturas entre $18^{\circ} \mathrm{C}$ e $23^{\circ} \mathrm{C}$ e de $29^{\circ} \mathrm{C}$ a $35^{\circ} \mathrm{C}$, foram restritas, e valores de temperatura menores que $18^{\circ} \mathrm{C}$ e maiores que $35^{\circ} \mathrm{C}$, inaptas. Com relação à pluviosidade, zonas consideradas aptas compreenderam uma quantidade de 830 a $3.000 \mathrm{~mm}$ ano $^{1}$, sendo que valores menores que 830 e maiores que 3.000 , foram inaptas. Para a aptidão edáfica, foram consideradas aptas as regiões contendo os mesmos tipos de solos existentes na região de origem do mogno (Argissolo, Latossolo, Neossolo, Quartzarênico, Litólico, Insular e Equatorial). A partir das características edafoclimáticas determinou-se que 55,62\% da área brasileira foi considerada apta, $11,66 \%$ apta com restrições leves, $25,00 \%$ apta com restrições moderadas e 7,71 \% restrita.

Palavras-chave: manejo florestal; clima e solo; crescimento e desenvolvimento vegetal.
\end{abstract}

\section{ABSTRACT}

The African mahogany (Khaya ivorensis A. Chev.) is a tree native from African continent, which has good quality wood and is used in furniture, shipbuilding, doors, among others. This work aimed to verify the Brazilian regions with climate and soil aptitude to the African mahogany. Rainfall, temperature and types of soil were used with variables of reference, from mahogany origin region, especially in the West African coast. From those variables, it was elaborated a selection criterion of regions considered apt, low apt and unapt to the appropriate mahogany growth and development. Brazilian regions that showed range of temperatures between $23^{\circ} \mathrm{C}$ and $29^{\circ} \mathrm{C}$ were considered apt, range from $18^{\circ} \mathrm{C}$ to $23{ }^{\circ} \mathrm{C}$ and from $29^{\circ} \mathrm{C}$ to $35^{\circ} \mathrm{C}$ were considered low apt, and when the range of temperature was lower than $18^{\circ} \mathrm{C}$ and higher than $35^{\circ} \mathrm{C}$, unapt. To rainfall variable, areas with amount from 830 to $3000 \mathrm{~mm}$ year ${ }^{1}$ were considerate apt, with

1 Engenheiro Agrônomo, Dr., Professor Adjunto no Setor de Engenharia de Biossistemas, Escola de Agronomia, Universidade Federal de Goiás, Rodovia Goiânia-Nova Veneza, Km 0, s/n, Campus Samambaia, CEP 74690-900, Goiânia (GO), Brasil. derblai@ufg.br / josealvesufg@yahoo.com.br

2 Tecnólogo em Gestão Ambiental, MSc., Programa de Pós-graduação em Agronomia, Universidade Federal de Goiás, Rodovia Goiânia-Nova Veneza, Km 0, s/n, Campus Samambaia, CEP 74690-900, Goiânia (GO), Brasil. flaviodeoliveirarosa@gmail.com

3 Engenheiro Agrícola, Dr., Professor Adjunto no Setor de Engenharia de Biossistemas, Escola de Agronomia, Universidade Federal de Goiás, Rodovia Goiânia-Nova Veneza, Km 0, s/n, Campus Samambaia, CEP 74690-900, Goiânia (GO), Brasil. awpego@pq.cnpq.br

4 Engenheira Agrônoma, Escola de Agronomia, Universidade Federal de Goiás, Rodovia Goiânia-Nova Veneza, Km 0, s/n, Campus Samambaia, CEP 74690-900, Goiânia (GO), Brasil. barbara_brito1@yahoo.com.br

5 Engenheiro Agrônomo, MSc., Professor Assistente no Setor de Engenharia de Biossistemas, Escola de Agronomia, Universidade Federal de Goiás, Rodovia Goiânia-Nova Veneza, Km 0, s/n, Campus Samambaia, CEP 74690-900, Goiânia (GO), Brasil. diogospena@hotmail.com

Recebido para publicação em 22/12/2015 e aceito em 22/11/2016

Ci. Fl., v. 28, n. 1, jan.- mar., 2018 
values less than 830 and higher than 3000 were unapt. Apt regions, to edaphic characteristics, were those that contain the same types of soils found in the origin region of Khaya ivorensis A. Chev. (Ultisol, Oxisol, Neossolo, Quartzarenic Litholic, Insular and Equatorial). From the soil and climate characteristics was determined that $55.62 \%$ of Brazil area was declared apt, $11.66 \%$ apt with slight restrictions, $25.00 \%$ apt with mean restriction and $7.71 \%$ restricted.

Keywords: forest management; climate and soil; plant growth.

\section{INTRODUÇÃO}

Nas últimas décadas, as acentuadas explorações de espécies florestais nativas, provocaram significativa diminuição de madeiras nobres, especialmente no hemisfério sul, em países de clima tropical e subtropical. No Brasil, na região Amazônica, as taxas de desmatamento aumentaram a partir de 1991, atingindo um ponto de máxima em 2004, sendo decrescente a partir deste ponto (INSTITUTO NACIONAL DE PESQUISAS ESPACIAIS, 2006). Ressalta-se que madeiras obtidas a partir do reflorestamento têm mostrado uma nova tendência de mercado, pois estas são empregadas de forma mais racional, além de serem legalizadas (SOUZA, 2012). A implantação de sistemas florestais é uma prática economicamente viável e apresenta benefícios ambientais, pois reduz a pressão sobre os ecossistemas naturais (CASTRO, 2008). Tais sistemas podem ser responsáveis por atender, não somente, à demanda de produtos madeireiros, mas também, produtos diversos, como resinas e substâncias medicinais, sobretudo, espécies da família das Meliáceas, como é o mogno, que possuem compostos antifúngicos, anti-inflamatórios, preventivos contra a malária e inseticidas (AGBEDAHUNSI; FAKOYA; ADESANYA, 2004; ABDELGALEIL; HASHINAGA; NAKATANI, 2005; ZHANG et al., 2009). Além disto, a implantação de florestas comerciais é importante tanto para diminuir o deficit florestal quanto para a proteção dos remanescentes nativos e fixação de carbono (RIBEIRO; MORI; MENDES, 2011; FERREIRA et al., 2012).

Em termos mundiais, durante o período de 2000 a 2010, cerca de 13 milhões de hectares de florestas nativas foram anualmente convertidas, a rigor, em agricultura e/ou pastagens, ou ainda, perderam-se em decorrência de causas naturais (MOURA; ZANCHETTA; LUCA, 2011). Este montante foi menor quando comparado aos 16 milhões de hectares anuais observados na década de 1990 (SOARES; MOTTA, 2010). $\mathrm{Na}$ América do Sul e na África observou-se a maior perda líquida anual das florestas no intervalo temporal de 2000 a 2010, com 4,0 e 3,4 milhões de hectares, respectivamente (MENDES, 2004).

Como alternativa de madeira nobre para atender ao mercado futuro, o mogno-africano vem ganhando espaço no Brasil, principalmente a espécie Khaya ivorensis A. Chev., graças aos bons resultados apresentados em pesquisas da Embrapa, sendo uma das espécies preferidas pelos reflorestadores no estado do Pará. Esta espécie tem grande importância econômica para a região Amazônica, em função do seu elevado valor comercial, e por ter crescimento relativamente rápido, o que possibilita a recuperação de áreas degradadas (FALESI; BAENA, 1999; POLTRONIERI et al., 2002). Além disto, o mogno-africano apresenta resistência à broca-do-ponteiro (Hypsipyla grandella Zeller), comum no mogno-brasileiro (POLTRONIERI et al., 2002), o que representa uma vantagem técnica e econômica desta espécie.

A carência de informações que retratem condições ideais para a implantação da cultura do mognoafricano implica menor produção e, consequentemente, prejuízos financeiros. O zoneamento edafoclimático constitui uma importante ferramenta, contribuindo na realização de um cultivo planejado, sendo que, a utilização dos recursos naturais de forma racional reflete na otimização dos investimentos, sendo necessário buscar atualizações que venham elevar a produtividade e minimizar custos e riscos que comprometam a atividade (ROCHA, 1997; SEDYIAMA et al., 2001).

No que se refere à produtividade florestal, o clima é um dos fatores que pode afetá-la diretamente, sendo este, uma variável que menos possibilita intervenções, pois permite algum controle apenas em cultivo protegido ou em áreas pequenas, nos quais se justificam investimentos financeiros (RIBEIRO, 2009). As variáveis climáticas são influenciadas pelo relevo, altitude e exposição das serras (SIQUEIRA et al., 2004), sendo o clima, um fator limitante e condicionante do cultivo das espécies florestais. As áreas aptas possuem características peculiares do meio físico (clima e solo) e das necessidades ecofisiológicas das espécies de interesse (FRITZSONS et al., 2012). Deste modo, o zoneamento edafoclimático é fundamental na tomada de decisões, uma vez que avalia a compatibilidade entre espécies cultivadas e o ambiente, de modo a 
caracterizar e delimitar regiões com maior ou menor aptidão, nas quais ocorre melhor adaptação da espécie de interesse.

Os mapas de zoneamento gerados com o uso de geoestatística e sistema de informação geográfica podem definir áreas com maior potencial de implantação da cultura de interesse (CASTRO, 2008). Assim, o objetivo deste trabalho foi realizar o zoneamento edafoclimático para a cultura do mogno-africano no Brasil.

\section{MATERIAL E MÉTODOS}

A detecção de zonas com maior e menor aptidão edafoclimática do mogno-africano (Khaya ivorensis A. Chev.) baseou-se em características de clima (GREY, 1979; FREEMETEO, 2013) e de solo (UNITED STATES DEPARTMENT OF AGRICULTURE, 1999) da região de origem desta espécie vegetal. Pois, a formação florestal savânica apresenta feições similares em cada continente, tendo influência das interações climáticas e dos eventos geológicos (COLE, 1986).

Foram levantados dados de onze países da Costa Ocidental Africana: Libéria, Costa do Marfim, Gana, Togo, São Tomé e Príncipe, Nigéria, Camarões, Gabão, República do Congo, República Democrática do Congo e Angola. Estes países possuem clima AW/AS, segundo a classificação climática descrita por Köppen e Geiger (1928), sendo que esta classificação é capaz de identificar aspectos geográficos e climatológicos (BURGOS, 1958). A partir desta caracterização foi possível estabelecer critérios de exigências edafoclimáticas do mogno-africano. Assim, com base nos conceitos de temperatura basal inferior, superior e ótima para o crescimento vegetal, estabeleceu-se que: as temperaturas basais inferiores $\left(18^{\circ} \mathrm{C}\right)$ e superiores $\left(35^{\circ} \mathrm{C}\right)$ foram obtidas a partir da temperatura mínima e máxima atingidas na região de origem (Tabela 1); já a faixa ótima foi determinada com base na média das temperaturas mínimas $\left(23,5^{\circ} \mathrm{C}\right)$ e máximas $\left(29,5^{\circ} \mathrm{C}\right)$ de todos os países (Tabela 1$)$; e a temperatura ótima foi a média das temperaturas médias dos países $\left(27,5^{\circ} \mathrm{C}\right)$.

Depois de estabelecidas as faixas de exigências, estas foram relacionados às normais climatológicas de temperatura e pluviosidade anual (IBAMA, 2013) e aos tipos de solos brasileiros (EMBRAPA, 2006; IBGE, 2013), possibilitando a confecção de mapas específicos. As variáveis latitude e longitude usadas para gerar o modelo foram extraídas das posições geográficas das estações citadas acima, e as altitudes foram geradas pelo SRTM (Shuttle Radar Topography Mission). As imagens SRTM foram obtidas diretamente no site do projeto GLCF (Global Land Cover Facility) no formato GEOTIFF com resolução espacial de 90 metros, resolução radiométrica de 16 bits e datum horizontal WGS-84. Ferreira, Valladares e Hott (2006) citam que o uso das imagens SRTM pode ser usado com boa precisão e confiabilidade para determinar as altitudes que serão usadas para compor o modelo.

Primeiramente, geraram-se os "mapas-base" de precipitação, temperatura e solos. Na geração dos mapas de temperatura e precipitação utilizou-se a ferramenta Interpolate to Raster da extensão Spatial Analyst, sendo o método de interpolação a Krigagem Ordinária, para se estimar os valores climáticos para as diversas regiões do estado que não continham postos meteorológicos com registros climáticos. Este método de interpolação vem sendo muito utilizado, tanto pela sua simplicidade quanto pelos resultados satisfatórios que proporciona. É um método local, em que a estimativa em um ponto não amostrado resulta da combinação linear dos valores encontrados na vizinhança (YAMAMOTO; LANDIM, 2013). Por outro lado, o mapa de solos foi gerado a partir do desmembramento do plano de informação (PI) de solo em dez PIs, por meio da ferramenta Select, em que foi criado um PI para cada tipo de solo, predominante na região de origem do mogno-africano. Os processamentos foram realizados no software ArcGIS.

Para avaliação do modelo ajustou-se uma equação de regressão linear simples aos dados de temperatura estimados e observados, nos quais se aplicaram o teste de correlação "r" de Pearson, o coeficiente de determinação $\mathrm{R}^{2}$ e o índice de concordância "d" de Willmott.

\section{RESULTADOS E DISCUSSÃO}

As médias climáticas de precipitação anual, temperatura média anual, temperatura máxima anual, temperatura mínima anual e tipos de solos predominantes na região de origem do mongo-africano (Khaya 
ivorensis A. Chev.) encontram-se na Tabela 1.

TABELA 1: Precipitação média anual $(\mathrm{mm})$, temperatura média, máxima e mínima anual $\left({ }^{\circ} \mathrm{C}\right)$ e classes predominantes de solos, para os países que formam a região de origem da cultura do mogno-africano (Kaya ivorensis A. Chev.).

TABLE 1: Average mean rainfall ( $\mathrm{mm})$, average, maximum and minimum annual temperature $\left({ }^{\circ} \mathrm{C}\right)$ and predominant soil classes, to the origin countries of African mahogany (Kaya ivorensis A. Chev.).

\begin{tabular}{|c|c|c|c|c|c|c|}
\hline Países & $\mathrm{P}$ & $\mathrm{T}_{\mathrm{m}}$ & $\mathrm{T}_{\max }$ & $\mathrm{T}_{\min }$ & Clima & Solo \\
\hline Libéria & $>2.000$ & 25 & 27 & 24 & Equatorial & - \\
\hline Costa do Marfim & 1.300 & 27 & 32 & 22 & $\begin{array}{l}\text { Tropical e } \\
\text { semiárido }\end{array}$ & Argissolo \\
\hline Gana & 830 & 23 & 28 & 25 & Tropical & Argissolo \\
\hline Togo & $<1.000$ & 27 & 35 & 20 & Tropical & Argissolo \\
\hline Nigéria & $>1.000$ & 30 & 37 & 23 & $\begin{array}{l}\text { Tropical- } \\
\text { úmido }\end{array}$ & Insular e Equatorial \\
\hline Camarões & 3.000 & 23 & 28 & 18 & Equatorial & $\begin{array}{c}\text { Latossolo, Neossolo quartzarênico, } \\
\text { Argissolo }\end{array}$ \\
\hline Gabão & $>3.000$ & 25 & 32 & 23 & $\begin{array}{l}\text { Equatorial } \\
\text { quente } \\
\text { úmido }\end{array}$ & Latossolo, Neossolo Litólico, Argissolo \\
\hline República do Congo & $>1.200$ & 23 & 20 & 27 & $\begin{array}{l}\text { Equatorial } \\
\text { quente } \\
\text { úmido }\end{array}$ & $\begin{array}{c}\text { Latossolo, Neossolo quartzarênico, } \\
\text { Argissolo }\end{array}$ \\
\hline $\begin{array}{c}\text { República } \\
\text { Democrática do } \\
\text { Congo }\end{array}$ & 1.500 & 25 & 26 & 24 & $\begin{array}{l}\text { Tropical } \\
\text { úmido e } \\
\text { semiárido }\end{array}$ & Argissolo e Latossolo \\
\hline Angola sem deserto & 1.200 & 24 & 15 & 35 & Tropical & Neossolo Litólico, Argissolo \\
\hline
\end{tabular}

Em que: $\mathrm{P}=$ Precipitação média anual. $\mathrm{T}_{\mathrm{m}}=$ Temperatura média anual. $\mathrm{T}_{\max }=$ Temperatura máxima anual. $\mathrm{T}_{\min }=$ Temperatura mínima anual. Fonte: FreeMeteo (2013) e Grey (1979).

Já as normais climatológicas de precipitação e temperatura, bem como, os tipos de solos brasileiros, estão apresentados nas Figuras 1a; 1b; 1c, respectivamente. Ressalta-se que as estimativas de temperatura apresentaram valores de coeficiente de correlação de Pearson $r=0,81$, de determinação $\mathrm{R}^{2}=0,78$ e índice de Wilmott $\mathrm{d}=0,86$.

Utilizando a metodologia de Krigagem ordinária foram estabelecidas seis classes de precipitação pluviométrica anual, as quais variaram de 150 a $3.625 \mathrm{~mm}$, nove classes para a temperatura média anual, variando desde $13^{\circ} \mathrm{C}$ até $29^{\circ} \mathrm{C}$, e 37 classes de solos (Figura 1). 


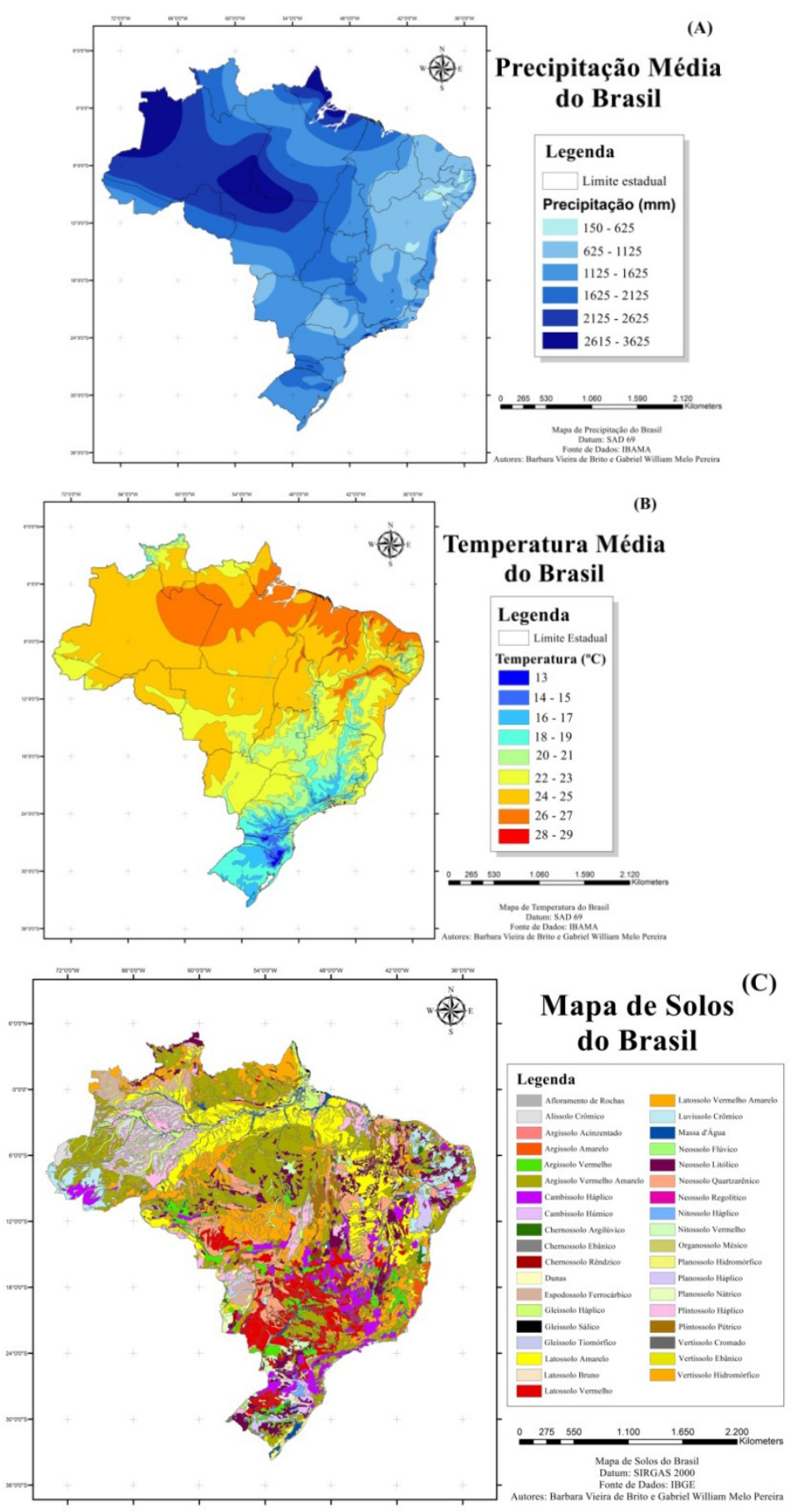

FIGURA 1: Mapas de Precipitação (A), Temperatura (B) e Solos (C) do Brasil. FIGURE 1: Maps from Rainfall (A), temperature (B) and soils (C) of Brazil.

Os dois semivariogramas (temperatura e precipitação) foram testados e os erros estatísticos das interpolações foram obtidos a partir da validação cruzada (Tabela 2). 
TABELA 2: Erros da validação cruzada para os dois atributos estudados.

TABLE 2: Cross-validation errors for both attributes studied.

\begin{tabular}{lcc}
\hline \multirow{2}{*}{ Erros } & \multicolumn{2}{c}{ Atributos } \\
\cline { 2 - 3 } & Temperatura & Precipitação \\
\hline Média & 0,0737 & $-5,8331$ \\
Erro Quadrático Médio & 1,9350 & 272,30 \\
Média Padrão & $-0,034$ & $-0,01606$ \\
Erro Médio Quadrático Normal & 5,8548 & 0,79238 \\
Erro Médio Padrão & 1,3268 & 342,985 \\
\hline
\end{tabular}

A Tabela 3 apresenta os resultados dos parâmetros estimados para o modelo ajustado e as componentes analisadas dos semivariogramas feitos a partir das variáveis tabuladas.

TABELA 3: Parâmetros estimados para cada atributo.

TABLE 3: Parameters estimated for each attribute.

\begin{tabular}{lccc}
\hline Atributos & Pepita & Alcance & Patamar \\
\hline Temperatura & 0 & 1,966 & 3,454 \\
Precipitação & $101.986,7$ & 0,593 & $2.153,97$ \\
\hline
\end{tabular}

As Figuras 2a e 2b mostram os semivariogramas experimentais das variáveis estudadas.
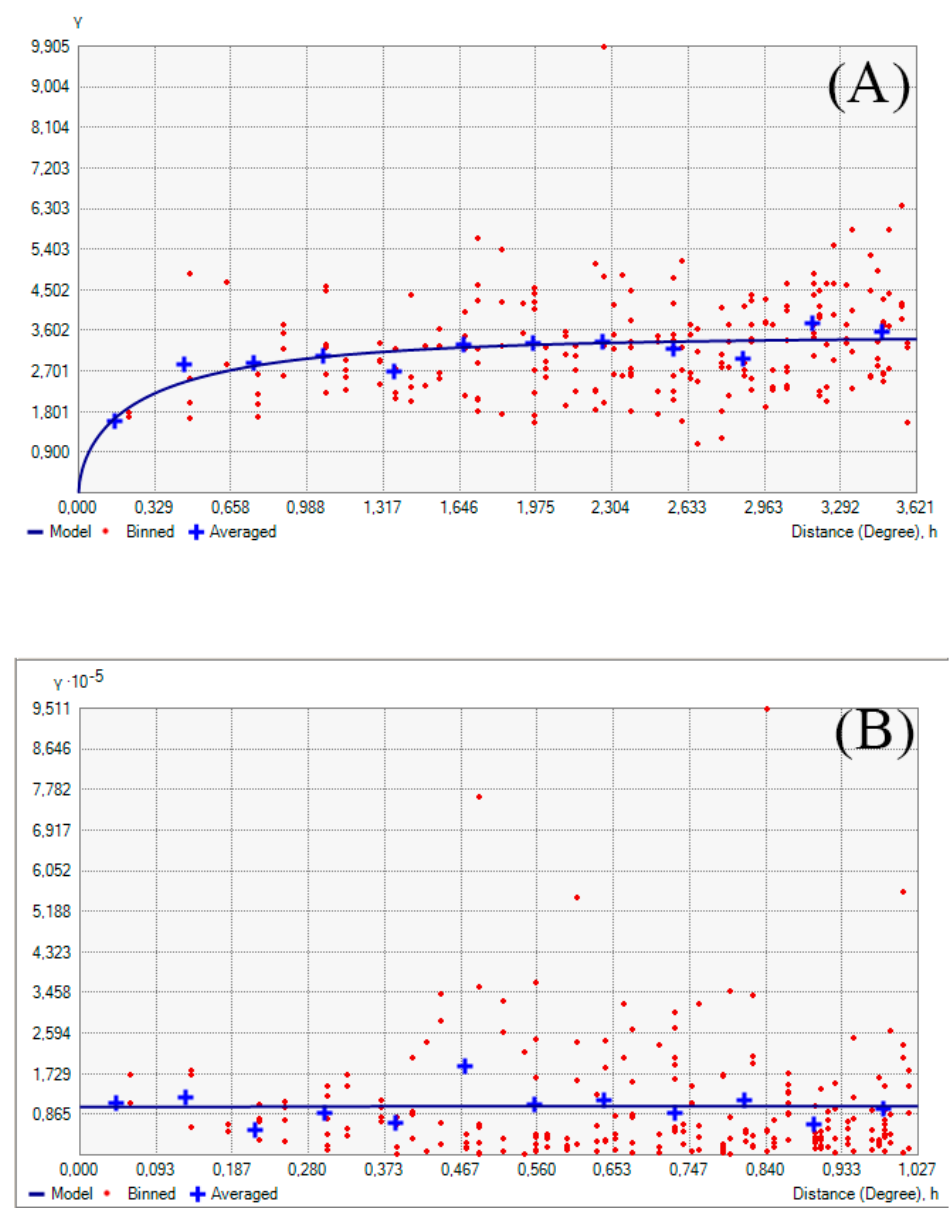

FIGURA 2: Modelo de semivariograma para temperatura do ar (A) e precipitação pluvial (B).

FIGURE 2: Semi-variogram model for air temperature (A) and rainfall (B). 
A obtenção das faixas de temperatura adequadas para o crescimento e desenvolvimento do mognoafricano (Khaya ivorensis A. Chev.) fundamentou-se nos conceitos de temperatura base, ótima e máxima para o crescimento vegetal, assim, estabeleceu-se que temperaturas na faixa entre $18^{\circ} \mathrm{C}$ e $35^{\circ} \mathrm{C}$ são aptas, menores que $18^{\circ} \mathrm{C}$ e maiores que $35^{\circ} \mathrm{C}$ são inaptas (Figura 3), estabelecidas com base na região de origem do mogno.

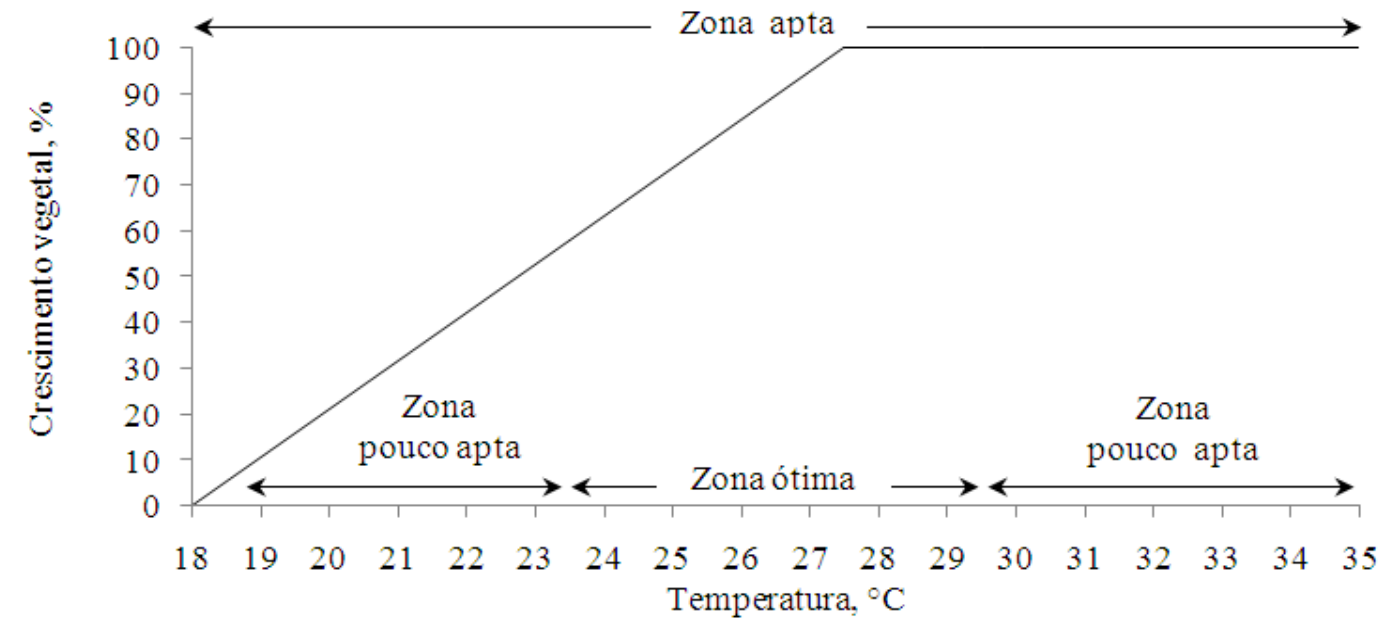

FIGURA 3: Zonas de aptidão da variável temperatura para o cultivo do mogno-africano - Zonas Aptas $\left(18^{\circ} \mathrm{C} \leq \mathrm{T}\right.$ $\left.\leq 35^{\circ} \mathrm{C}\right)$, Ótima $\left(23,5^{\circ} \mathrm{C} \leq \mathrm{T} \leq 29,5^{\circ} \mathrm{C}\right)$, Pouco Aptas $\left(18^{\circ} \mathrm{C} \leq \mathrm{T} \leq 23,5^{\circ} \mathrm{C} ; 29,5^{\circ} \mathrm{C} \leq \mathrm{T} \leq 35^{\circ} \mathrm{C}\right)$ e Inaptas $\left(18^{\circ} \mathrm{C}>\mathrm{T}>35^{\circ} \mathrm{C}\right)$.

FIGURE 3: Zones of aptitude from air temperature to African Mahogany - apt $\left(18^{\circ} \mathrm{C} \leq \mathrm{T} \leq 35^{\circ} \mathrm{C}\right)$, optimum $(23,5$ $\left.{ }^{\circ} \mathrm{C} \leq \mathrm{T} \leq 29,5^{\circ} \mathrm{C}\right)$, little apt $\left(18^{\circ} \mathrm{C} \leq \mathrm{T} \leq 23,5^{\circ} \mathrm{C} ; 29,5^{\circ} \mathrm{C} \leq \mathrm{T} \leq 35^{\circ} \mathrm{C}\right)$ and unapt $\left(18^{\circ} \mathrm{C}>\mathrm{T}>35^{\circ} \mathrm{C}\right)$.

Para a precipitação pluvial, consideraram-se aptas as regiões com intensidades na faixa entre 830 e $3.000 \mathrm{~mm} \mathrm{ano}^{-1}$, tais valores se referem à menor e à maior precipitação encontrada na região de origem, sendo inaptas as áreas com precipitação inferior a 830 e superior a $3.000 \mathrm{~mm}$ ano ${ }^{-1}$. Vale ressaltar que, embora Angola tenha apresentado uma precipitação $660 \mathrm{~mm} \mathrm{ano}^{-1}$, portanto, inferior à mínima considerada neste estudo, essa média de precipitação não foi levada em consideração, tendo em vista que o país apresenta uma região desértica, fazendo com que a média precipitada decresça de forma discrepante com relação aos demais valores.

$\mathrm{Na}$ Costa Ocidental Africana verificaram-se as predominâncias dos seguintes tipos de solos: Argissolo, Latossolo, Insular, Equatorial, Neossolo quartzarênico e Neossolo litólico (UNITED STATES DEPARTMENT OF AGRICULTURE, 1999). Sendo que alguns destes solos também são encontrados nas diferentes regiões brasileiras, tais como: Argissolo, Latossolo e Neossolos (EMBRAPA, 2006; IBGE, 2013). Desta forma, zonas edáficas aptas foram aquelas que apresentaram o mesmo tipo de solo, entre a região de origem e as regiões brasileiras, e inaptas, com tipos de solos diferentes.

A partir da união das informações referentes às exigências edafoclimáticas do mogno-africano e as condições de clima e solo brasileiros, foram criadas classes de aptidão para a implantação desta cultura, nas quais se considerou: i) apta: quando todas as variáveis fossem aptas; ii) aptas com restrições leves: se apenas uma variável fosse pouco apta ou inapta; iii) aptas com restrições moderadas: se ao menos duas variáveis fossem pouco aptas ou inaptas; iv) restrita: caso duas variáveis fossem pouco aptas e inaptas, ou apresentarem duas variáveis inaptas; v) inapta: todas as variáveis consideradas inaptas (Tabela 4). 
TABELA 4: Classes de aptidão edafoclimática para a cultura do mogno-africano.

TABLE 4: Edaphoclimatic aptitude class to African mahogany.

\begin{tabular}{cccc}
\hline Classes de aptidão & Solo & Temperatura & Precipitação \\
\hline Apto & Apto & Apta $\left(24^{\circ} \mathrm{C} \mathrm{a} 29,5^{\circ} \mathrm{C}\right)$ & Apta $\left(830\right.$ a $\left.3.000 \mathrm{~mm} \mathrm{ano}^{-1}\right)$ \\
Apto com restrições leves & Apto & Pouco Apta $\left(18^{\circ} \mathrm{C} \mathrm{a} 23,5^{\circ} \mathrm{C}\right)$ ou & Apta \\
& Apto & $\left(29,5^{\circ} \mathrm{C} \mathrm{a} 35^{\circ} \mathrm{C}\right)$ & Inapta $\left(<830\right.$ ou $\left.>3.000 \mathrm{~mm} \mathrm{ano}^{-1}\right)$ \\
Apto com restrições & Apto & Apta & Inapta \\
moderadas & Apto & Inapta $\left(<18^{\circ} \mathrm{C} \mathrm{ou}>35^{\circ} \mathrm{C}\right)$ & Apta \\
& Inapto & Apta & Apta \\
& Inapto & Pouco Apta & Inapta \\
Restrito & Inapto & Pouco Apta & Inapta \\
& Inapto & Apta & Apta \\
Inapto & Inapto & Inapta & Inapta \\
\hline
\end{tabular}

Com base nestes critérios, a interpolação, utilizando o método de Krigagem Ordinária, obteve os produtos cartográficos denominados de mapa de aptidão climática (Figura $4 \mathrm{~A}$ ) e mapa de aptidão edafoclimática (Figura 4B) para a cultura do mogno-africano no Brasil.

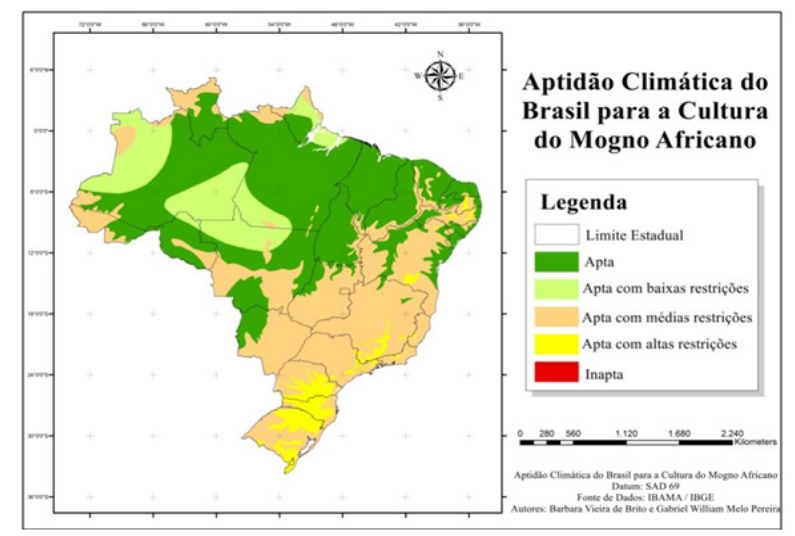

(A)

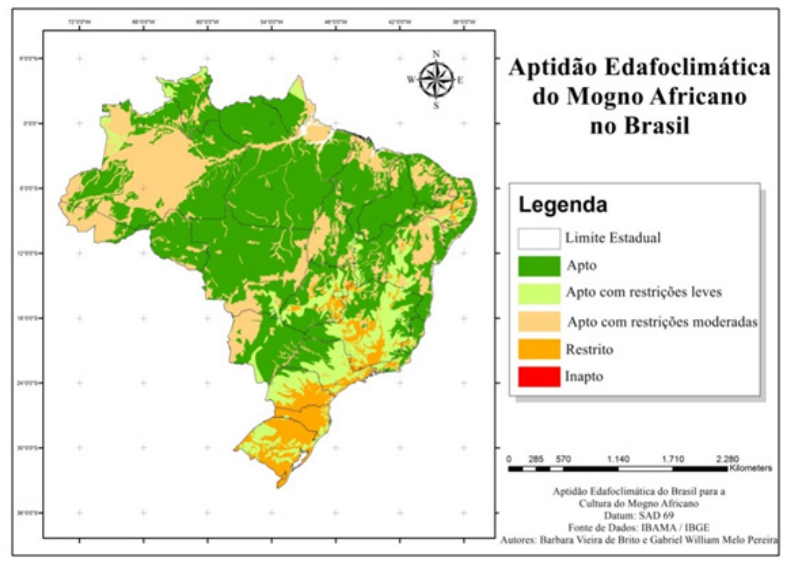

(B)

FIGURA 4: Mapa de aptidão climática (A) e edafoclimática (B) do mogno-africano no Brasil.

FIGURE 4: Climatic (A) and edaphoclimatic (B) aptitude maps to African Mahogany in Brazil. 
Considerando apenas as variáveis climáticas, observa-se que o Brasil é predominantemente apto e apto com restrições para o cultivo do mogno-africano (Figura 4A). Assim, 45,72 \% do território brasileiro foi considerado climaticamente apto, $17,12 \%$ apto com baixas restrições, 31,68 \% apto com médias restrições, 5,44\% apto com altas restrições e $0,04 \%$ inapto. Com relação à classificação edáfica, 70,07 $\%$ foi considerado apto e $29,93 \%$ inapta. A partir da sobreposição das características de clima e de solo, classificação edafoclimática (Figura 4B), verificou-se que 55,62 \% foi descrito como apto, 11,66 \% apto com restrições leves, $25,00 \%$ apto com restrições moderadas e 7,71 \% restrito.

A região sul do Brasil apresenta uma menor aptidão em relação às demais regiões. Isto se deve, sobretudo, pelas restrições térmicas (temperatura do ar), podendo limitar o crescimento e o desenvolvimento desta espécie em determinados períodos do ano, em que se observam temperaturas inferiores a $18^{\circ} \mathrm{C}$. Ainda, na mesma figura, foi identificada uma pequena região inapta no país $(0,01 \%)$, localizada próximo ao litoral do Estado de São Paulo.

Foram considerados predominantemente aptos, ou seja, apto ou apto com restrições leves para o plantio do mogno, os estados do Amapá, Goiás, Tocantins, Ceará, Rondônia, Roraima, Pará, Piauí e grande parte do Mato Grosso, além do sul e sudoeste do Maranhão, norte, nordeste e sul de Mato Grosso do Sul, norte e leste da Amazônia, e também, quase toda região litorânea, estendendo-se desde o estado do Rio Grande do Norte até a região norte do estado do Rio de Janeiro (Figura 4).

O cultivo de mogno no Brasil vem aumentando de modo significativo em função de sua boa adaptação ao território brasileiro, por ser uma espécie que tolera grande variação climática. A espécie Khaya ivorensis A. Chev. ou mogno-africano é encontrado em florestas úmidas e em zonas subtropicais (830 a $\left.3.000 \mathrm{~mm} \mathrm{ano}^{-1}\right)$, porém, não há registro natural de ocorrência em áreas mais secas, mesmo em seu continente de origem, como a região desértica da Angola (WHITMORE, 1983). Já o mogno-sul-americano (Swietenia macrophylla King.) é, geralmente, encontrado bem adaptado em florestas tropicais secas, com temperatura anual média de $24^{\circ} \mathrm{C}$ e precipitação anual entre 1.000 a $2.000 \mathrm{~mm}^{\text {ano }}{ }^{-1}$ (GULLISON et al., 1996; LAMB, 1996; GROGAN; BARRETO; VERÍSSIMO, 2002; SOUZA, 2010).

O nim (Azadirachta indica A. Juss.), da mesma família do mogno (Meliácea), possui um adequado crescimento vegetal em áreas com chuvas anuais entre 800 e $1800 \mathrm{~mm}$ anuais, todavia, em regiões com temperaturas médias do ar de $20^{\circ} \mathrm{C}$ (MOSSINI; KEMMELMEIER, 2005), inferiores às áreas consideradas aptas sem restrições para o mogno-africano no presente estudo.

O potencial adaptativo do mogno-africano às condições climáticas brasileiras possui similaridades ao potencial adaptativo da Tectona grandis L. f. (PANDEY; BROWN, 2000; FONSECA, 2004; FIGUEIREDO; OLIVEIRA, L. C.; BARBOSA, 2005), pois ambas as espécies exigem climas tropicais úmidos e quentes, com precipitação entre 1.300 a $2.500 \mathrm{~mm}^{a n o^{-1}}$. A Tectona grandis L. f. obtém adequado crescimento e desenvolvimento em uma ampla faixa de temperatura do $\operatorname{ar}\left(13^{\circ} \mathrm{C}\right.$ a $\left.43^{\circ} \mathrm{C}\right)$, em estação seca, apresentando disponibilidade hídrica inferior a $50 \mathrm{~mm} \mathrm{mês}^{-1}$ (FONSECA, 2004). Desta forma, esta capacidade adaptativa das espécies se constitui em uma importante alternativa quanto à diversificação de atividades, bem como agregação de valor para o produtor.

Segundo Kiehl (1979), solos profundos com boa drenagem e fertilidade razoável permitem bom desenvolvimento da Tectona grandis L. f., podendo tolerar solos de textura que variam de arenoso e francoargiloso. Por outro lado, a implantação desta em solos mal drenados, com lençol freático superficial e em solos com elevada acidez, torna-se uma prática inviável. Isto corrobora os estudos realizados com o nim, que tem seu melhor desenvolvimento em solos arenosos, profundos e bem drenados, com $\mathrm{pH}$ entre 6,5 e 7,5. Estas características pedológicas podem ser comuns às exigidas pelo mogno, tendo em vista as similaridades em termos de adaptabilidade ambiental destas plantas (FONSECA, 2004; MOSSINI; KEMMELMEIER, 2005).

Já em estudos com Pinus maximinoi, em solos argilosos de países da América Central, constatou-se uma boa adaptação desta espécie em ambientes com precipitação variando de $900 \mathrm{~mm}$ a $2.200 \mathrm{~mm}^{2} \mathrm{ano}^{-1}$, mesmo havendo estação seca bem definida (FRITZSONS et al., 2012). Embora sejam espécies de famílias distintas e por consequência exigências distintas de adaptação quanto às características edafoclimáticas, ficou demonstrado que a existência de similaridade em relação à exigência hídrica entre Pinus maximinoi e o mogno-africano (Khaya ivorensis A. Chev.) são preponderantes na determinação da adaptabilidade dessas espécies. 
A carência de informações referentes aos solos viáveis também é tema de discussões em outras espécies, como o Pinus maximinoi, dificultando, assim, estudos de zoneamento edáfico (FRITZONS et al., 2012). Este fato foi observado neste estudo do zoneamento edáfico do mogno-africano, que levou ao estabelecimento de critérios comparativos entre os solos predominantes nos países de origem desta espécie, com os solos presentes no Brasil.

Vale ressaltar que as restrições apontadas neste estudo em determinadas áreas, como por exemplo, na região sul do Brasil (Figura 4b), demonstram possíveis dificuldades que as plantas poderão sofrer durante sua adaptação, no entanto, na literatura são encontrados apenas cultivos na região centro-oeste brasileira (BARBOSA et al., 2014; ROSA et al., 2014), não sendo determinado o crescimento do mogno-africano na região considerada restrita neste estudo.

Em estudos de zoneamentos edafoclimáticos torna-se importante definir uma ordem de prioridade aos fatores ambientais que influenciarão diretamente no crescimento vegetal, as diferentes categorias que estão ligadas a produtividade florestal. Na literatura encontra-se a proposta desta sequência: clima, relevo, textura e fertilidade do solo, apontando o clima como o responsável pelas maiores variações na produtividade, sendo seus efeitos notados em regiões extensas, enquanto as variáveis topográficas e pedológicas melhor explicam o crescimento arbóreo em pequenas regiões (GONÇALVES et al., 1999).

Para o estado de Goiás, estudos corroboram a existência de regiões edafoclimáticas aptas para o plantio do mogno-africano (BRITO et al., 2013; ROSA, 2014), os quais corroboram o encontrado neste estudo.

\section{CONCLUSÕES}

A partir do levantamento de temperatura média do ar, pluviosidade média anual, tipos de solos, provenientes da região de origem do mogno-africano, e das normas climatológicas de temperatura média do ar e pluviosidade anual, bem como dos tipos de solos das diferentes regiões do Brasil, foi possível, em ambiente SIG, a confecção de mapas que delimitaram zonas aptas, aptas com restrição, restritas e inaptas para o adequado crescimento e desenvolvimento do mogno-africano em território brasileiro, no qual se destacam as regiões Norte, Centro-Oeste e Nordeste como passíveis de produção e a região Sul, devendo-se observar suas limitações, sobretudo climáticas.

Entretanto, vale ressaltar que, estudos de campo, nas diferentes regiões edafoclimáticas do Brasil, deverão ser realizados para validar estas informações.

\section{AGRADECIMENTOS}

A UFG e a CAPES pelas bolsas de graduação e de pós-graduação fornecidas aos alunos de iniciação científica e de mestrado, os quais colaboraram com este trabalho. A empresa de produção de mudas "Mudas Nobres $^{\circledR}$ ", pela colaboração e pelo fornecimento de material a respeito da espécie Khaya ivorensis A. Chev.

\section{REFERÊNCIAS}

ABDElgaleIL, S. A. M.; HASHINAGA, F.; NAKATANI, M. Antifungal activity of limonoids from Khaya ivorensis. Pest Management Science, Sussex, v. 61, n. 2, p. 186190, 2005.

AGBEDAHUNSI, J. M.; FAKOYA, F. A.; ADESANYA, S. A. Study on the anti-inflammatory and toxic effects of the stem bark of Khaya ivorensis (Meliaceae) on rats. Phytomedicine, Jena, v. 11, n. 6, p. 504508, 2004.

BARBOSA, L. H. A. et al. Response of african mahogany trees to drip irrigation and fertilization levels. In: INOVAGRI INTERNATIONAL MEETING, 2., 2014, Fortaleza. Anais... Fortaleza: INOVAGRI, 2014. p. 2405-2413.

BRITO, B. V. et al. Aptidão edafoclimática da cultura do Mogno Africano para o Estado de Goiás utilizando uma ferramenta SIG. In: SIMPÓSIO BRASILEIRO DE SENSORIAMENTO REMOTO, 16., 2013, Foz do Iguaçú. Anais... São José dos Campos: INPE, 2013. p. 60-65.

BURGOS, J. J. Agroclimatic classifications and representations: report of the applications value 
of climatic and agroclimatic classification for agricultural purposes. Varsovia: WMO; Comission for Agricultural Meteorology, 1958. (CaMII/Doc., 18).

CASTRO F. S. Zoneamento agroclimático para a cultura do Pinus no Estado do Espírito Santo. 2008. 101 f. Dissertação (Mestrado em Produção Vegetal) - Universidade Federal do Espírito Santo, Alegre, 2008. COLE, M. M. The savannas: biogeography and geobotany. London: Academic Press, 1986. 438 p.

EMBRAPA. Centro Nacional de Pesquisa em Solos. Sistema brasileiro de classificação de solos. 2. ed. Rio de Janeiro: EMBRAPA, 2006. 360 p.

FALESI, I. C.; BAENA, A. R. C. Mogno-africano em sistema silvopastoril com leguminosas e revestimento natural do solo. Belém: Embrapa Amazônia Oriental, 1999. 52 p. (Documentos, 4).

FERREIRA, D. A. et al. Influência da posição das miniestacas na qualidade de mudas de cedro australiano e no seu desempenho inicial no pós-plantio. Ciência Florestal, Santa Maria, v. 22, n. 4, p. 715-723, 2012. FERREIRA, W. P. M.; VALLADARES, G. S.; HOTT, M. C. Estimativa da temperatura média mensal do ar para os estados de Minas Gerais e do Pará, utilizando-se Modelos Digitais de Elevação. Engenharia na Agricultura, v. 14, n. 4, p. 293-303, 2006.

FIGUEIREDO, E. O; OLIVEIRA, L. C.; BARBOSA, L. K. F. Teca (Tectona grandis L.F.): principais plantas do futuro empreendedor florestal. Rio Branco: Embrapa-AC, 2005. $87 \mathrm{p}$.

FONSECA, W. G. Manual para productores de Teca (Tectona grandis L.F.) en Costa Rica. Heredia: FONAFIFO, 2004. $121 \mathrm{p}$.

FREEMETEO. Tempo meteorológico e climas para cidades, vilarejos e topônimos no mundo. Disponível em: $<$ https://freemeteo.com.br $>$. Acesso em: maio 2013.

FRITZSONS, E. et al. Zoneamento climático para plantio experimental de Pinus maximinoi no Estado de São Paulo. Pesquisa Florestal Brasileira, Colombo, v. 32, n. 69, p. 79-92, 2012.

GONÇALVES, J. L. M. et al. Estabelecimento de reflorestamentos mistos com espécies típicas da Mata Atlântica, em função do cultivo mínimo ou intensivo do solo e do controle de plantas invasoras. Revista Árvore, Viçosa, MG, v. 23, n. 3, p. 259-70, 1999.

GREY, D. C. Site quality prediction for Pinus patula in the Glengarry area, Transkei. South African Forestry Journal, Pretoria, v. 111, n. 1, p. 44-8, 1979.

GROGAN, J.; BARRETO, P.; VERÍSSIMO, A. Mogno na Amazônia brasileira: ecologia e perspectivas Manejo. Belém: Imazon, 2002. 56 p.

GULLISON, R. E. et al. Ecology and management of mahogany (Swietenia macrophylla Ling) in the Chimanes Forest, Beni, Bolivia. Botanical Journal of the Linnean Society, London, v. 122, n. 1, p. 9-34, 1996.

IBAMA. Banco de dados meteorológicos. Disponível em: <http://www.ibama.gov.br/search/dadosmeteorologicos>. Acesso em: jan. 2013.

IBGE. Mapas de solos brasileiros. Disponível em: <http://mapas.ibge.gov.br/tematicos/solos $>$. Acesso em: fev. 2013.

INSTITUTO NACIONAL DE PESQUISAS ESPACIAIS (Brasil). Estimativas Anuais desde 1988: taxa de desmatamento anual ( $\left.\mathrm{km}^{2} / \mathrm{ano}\right)$. São José dos Campos: INPE, 2006. Disponível em: <http://www.obt. inpe.br/prodes/prodes_1988_2005.htm>.

KIEHL, E. J. Manual de edafologia: relações solo-planta. São Paulo: Agronomia Ceres, 1979. 264 p.

KÖPPEN, W.; GEIGER, R. Klimate der Erde. Gothia: Verlag Justus Perthes, 1928. (Wallmap. $150 \mathrm{~cm}$ x $200 \mathrm{~cm})$.

LAMB, F. B. Mahogany of Tropical America: its ecology an management. Ann Arbor: University of Michigan, 1996. 220 p.

MENDES, J. B. Incentivos e mecanismos financeiros para o manejo florestal sustentável na região Sul do Brasil. Curitiba: FAO, 2004. 136 p. (Relatório FAO - Food and Agriculture Organization of the United Nation).

MOSSINI, S. A. G.; KEMMELMEIER, C. A árvore Nim (Azadirachta indica A. Juss): múltiplos usos. Acta Farmmaceutica Bonaerense, Buenos Aires, v. 24, n. 1, p. 139-48, 2005.

MOURA, L. C.; ZANCHETTA, D.; LUCA, E. F. Gestão, sustentabilidade e enriquecimento da flora nativa em floresta plantada de eucalipto. In: CONGRESSO NACIONAL DE EXCELÊNCIA EM GESTÃO, 7., 2011, Rio de Janeiro. Anais... Rio de Janeiro: FIRJAN, 2011. 17 p. 
PANDEY, D.; BROWN, C. La teca: una visión global. Revista Internacional de Silvicultura y Industrias Forestales, Roma, v. 51, n. 201, p. 3-13, 2000.

POLTRONIERI, L. S. et al. Detecção de Phamerochaete salmonicolor em Mogno Africano no Estado do Pará. Fitopatologia Brasileira, Brasília, v. 27, n. 3, p. 321-321, 2002.

RIBEIRO, A. O.; MORI, F. A.; MENDES, L. M. Características das dimensões das fibras e análise do ângulo microfibrilar de Toona ciliata cultivada em diferentes localidades. Floresta, Curitiba, v. 41, n. 1, p. 47-56, 2011.

RIBEIRO, C. A. D. Delimitação de zonas agroclimáticas para a cultura do Eucalipto no norte do Espírito Santo e sul da Bahia. 2009. 102 f. Dissertação (Mestrado em Produção Vegetal) - Universidade Federal do Espírito Santo, Alegre, 2009.

ROCHA, J. M. Manual de projetos ambientais. Brasília: MMA, 1997. 446 p.

ROSA, F. O. et al. Crescimento e desenvolvimento do Mogno Africano cultivado em ambiente protegido e em campo. In: INOVAGRI INTERNATIONAL MEETING, 2., 2014, Fortaleza. Anais... Fortaleza: INOVAGRI, 2014. p. 2388-2393.

SEDIYAMA, G. C. et al. Zoneamento Agroclimático do cafeeiro (Coffea arábica L.) para o estado de Minas Gerais. Revista Brasileira de Agrometeorologia, Sete Lagoas, v. 9, n. 3, p. 501-509, 2001.

SIQUEIRA, J. D. P. et al. Estudo ambiental para os programas de fomento florestal da Aracruz Celulose S. A. e extensão florestal do Governo do Estado do Espírito Santo. Floresta, Curitiba, n. esp., p. 3-67, 2004. SOARES, S. C.; MOTTA, A. L. T. S. Diminuição das florestas naturais no mundo. In: CONGRESSO NACIONAL DE EXCELÊNCIA EM GESTÃO, 6., 2010, Niterói. Anais... Rio de Janeiro: FIRJAN, 2010. $22 \mathrm{p}$.

SOUZA, C. A. S. et al. Exigências nutricionais e crescimento de plantas de mogno (Swietenia macrophylla King.). Acta Amazônica, Manaus, v. 40, n. 3, p. 515-522, 2010.

SOUZA, F. M. Caracterização socioeconômica e ambiental de produtos florestais não madeireiros de famílias agroextrativistas, em quatro municípios de Goiás. 2012. 60 f. Dissertação (Mestrado em Ciências Florestais) - Universidade de Brasília, Brasília, 2012.

UNITED STATES DEPARTMENT OF AGRICULTURE. Soil taxonomy: a basic system of soil classification for making and interpreting soil surveys. 2nd ed. Washington: USDA, 1999. $863 \mathrm{p}$.

WHITMORE, J. L. Swietenia macrophylla and S. humilis (caoba, mahogany). In: JANZEN, D. H. (Ed.). Costa Rica natural history. Chicago: University of Chicago Press, 1983. p. 331-333.

YAMAMOTO, J. K.; LANDIM, P. M. B. Geoestatística: conceitos e aplicações. São Paulo: Oficina de Textos, 2013. $215 \mathrm{p}$.

ZHANG, B. et al. Limonoids from Khaya ivorensis. Phytochemistry, New York, v. 70, n. 10, p. 1305$1308,2009$. 